\title{
Soda-anthraquinone Pulping and Cationization of Posidonia oceanica
}

\author{
Ana Moral, ${ }^{\mathrm{a}, *}$ Roberto Aguado, ${ }^{\mathrm{a}}$ Raquel Roldán, ${ }^{\mathrm{a}}$ Antonio Tijero, ${ }^{\mathrm{b}}$ and \\ Menta Ballesteros ${ }^{\text {a }}$ \\ Every year, millions of tonnes of dead biomass from algae and seagrasses \\ are collected on the Mediterranean coasts. Posidonia oceanica is one of \\ the most abundant species. In this work, leaves and rhizomes from this \\ plant were pulped, alkalized, and cationized to make a value-added \\ product. The main effects of five separate pulping variables, namely \\ temperature, time, $\mathrm{NaOH}$ concentration, anthraquinone, and liquid-to-solid \\ ratio were studied. The total procedure to produce cationic fibers took only \\ $3 \mathrm{~h}$ (approximately), which made it a feasible process. A pseudo-second- \\ order rate equation was used to fit the results of chemical modification via \\ incorporation of quaternary ammonium ions. Characterization involved X- \\ ray diffraction, scanning electron microscopy, and elemental analysis. The \\ authors found that mild conditions were enough to achieve good results, \\ reaching degrees of substitution of 0.20 for leaves and 0.12 for rhizomes.
}

Keywords: Posidonia oceanica; Pulping; Alkalization; Cationization; X-ray diffraction; Scanning electron microscopy

Contact information: a: ECOWAL Group, Molecular Biology and Biochemical Engineering Department, Experimental Sciences Faculty, Pablo de Olavide University, Ctra. de Utrera km 1, 41013 Seville, Spain; b: Chemical Engineering Department, Faculty of Chemistry, Complutense University of Madrid. Av. Complutense s/n, 28040 Madrid, Spain; *Corresponding author: amoram@upo.es

\section{INTRODUCTION}

Recently, seaweed and seagrass have been described as promising sources of cellulose due to their lack of (most algae) or low (sea plants) content of lignin in the cell wall (Knoshaug et al. 2013; Syed et al. 2016; Tang et al. 2016). This is because lignification of the cell wall is the result of the evolution of land plants from sea species to give consistency to the cells of herbaceous and woody stalks (Peter and Neale 2004; Liitiä et al. 2014). This fact is particularly interesting because lignin is strongly related to the main environmental and economic issues in the extraction of cellulosic fibers from wood. Moreover, the chemical and structural properties of cellulose from marine plants and algae are similar to those of cellulose extracted from terrestrial species, as it shows the same Xray diffraction patterns and absorption spectra (Percival and Ross 1949).

Posidonia oceanica is one of the most abundant plants in the Mediterranean Sea (Ruíz et al. 2009), with its habitat reaching $40 \mathrm{~m}$ deep and supporting a rich biodiversity (Short et al. 2007). The wall of the epidermal cells contains cellulose, hemicellulose, and pectin, but no lignin, although it is present in low proportions in the leaves and in higher proportions in rhizomes or roots (Kuo and Cambridge 1978; Klap et al. 2000). A part of the dead leaves is dragged by the waves to deeper areas, while a higher proportion is transported and accumulated on the beach. The production of these plants is seasonal, varying the production and leaf morphology (Alcoverro et al. 1995). In autumn, conditions are optimal for growth, as there is greater availability of nutrients (Lepoint et al. 2002). 
The biomass from seagrass is massive in some beaches, with millions of tonnes of waste collected in the summer to avoid sanitary problems or impacts on local tourism (Syed et al. 2016). All these features justify the valorization of the dead biomass from $P$. oceanica to obtain cellulosic derivatives. In this sense, some researchers have proposed the use of cellulose extracted from $P$. oceanica as a starting material for carboxymethylcellulose (Aguir and M'Henni 2006; Khiari et al. 2011), sodium carboxymethylcellulose, cellulose acetate, and others (Coletti et al. 2013). Recently, it has been used as raw material to produce nanofibrillar cellulose (Bettaieb et al. 2015a,b), PLA nanocomposites (Fortunati et al. 2017), packaging materials (Benito-González et al. 2018), and films (BenitoGonzález et al. 2019). However, to the best of our knowledge, this is the first study on cationized cellulose from Posidonia oceanica, providing a new suggestion to reuse this dead biomass commonly found along Mediterranean coastlines.

Chemical modifications of cellulose and other polysaccharides have promoted new properties and applications of these compounds (Chopin et al. 2014). In recent years, cationized polysaccharides have been extensively studied to replace synthetic polymers in various applications (Cansee et al. 2008; Prado and Matulewicz 2014). Water-soluble cationic cellulose has been considered in a wide variety of manufacturing industries (Song et al. 2008) such as food, chemical cosmetic or pharmaceutical industries and in flocculation of effluents (Yan et al. 2009). Cationic fibers can enhance the absorption of anionic dyes in the textile industry, thus reducing the need for electrolyte baths and retention of fillers with negative surface charge in papermaking, partially substituting nonrenewable additives. Some environmental issues in dyeing and sheet forming are linked to the negative surface charge of native cellulose (Sood et al. 2010). Due to its antibacterial properties it can also be used for food packaging, wound healing and tissue engineering (Saini et al. 2016).

The most widely used process for the cationization of polysaccharides is etherification with 2-hydroxy-3-(N,N,N-trimethylammonium)propyl, obtained by reaction of the polysaccharide with 2,3-epoxypropyltrimethylammonium chloride (EPTAC) or synthesized from 3-chloro-2-hydroxypropyl chloride (CHPTAC). Other cationizing agents vary with respect to the alkyl groups attached to the quaternary ammonium. There is not a standardized protocol for the cationization of cellulosic fibers, as the process has not been widely implemented in the textile and paper industries and many factors influence the reaction (Kavaliauskaite et al. 2008). Therefore, the development of a methodology based on renewable cellulosic fibers for industrial-scale applications has a special interest.

The objective of this research was to study the sequential process of pulpingalkalization-cationization of cellulose fibers, using dead biomass of $P$. oceanica from a Mediterranean beach as the raw material. X-ray diffraction (XRD) and scanning electron microscopy (SEM) were used to interpret changes in the structure and morphology of the material after these chemical treatments. The incorporation of quaternary ammonium ions into cellulose during cationization was determined by elemental analysis and fitted to a kinetic model.

\section{EXPERIMENTAL}

\section{Materials}

Tidal residues were collected from the coast of Almeria (Spain) during the month of April 2015. Leaves and rhizomes (or trunks) of Posidonia oceanica were separated by 
hand and washed with fresh water, stored at room temperature for at least $24 \mathrm{~h}$ to reach equilibrium moisture, and cut to a particle size of $5 \mathrm{~mm}$ or smaller. Hydroxypropyltrimethylammonium chloride (CHPTAC), sodium polyvinylsulphate (PVSNa), olydiallyldimethylammonium chloride (PDADMAC), and anthraquinone were supplied by Merck \& Co. (Madrid, Spain). Sodium hydroxide $(\mathrm{NaOH})$ pellets were purchased from PanReac AppliChem (Barcelona, Spain).

\section{Methods}

Pulping

To determine the main effects on the cationization process of 5 separate variables during pulping (time, temperature, alkali charge, anthraquinone, and liquid-solid ratio or hydromodule), a simple star design was selected. The 10 assays listed in Table 1 imply one test at each extreme value of each of the 5 factors, while the other 4 factors were set at the intermediate level. The influence of these independent variables on the results of cationization was studied with OriginPro 8.5 (OriginLab Corporation, Northampton, MA, USA) software. Testing the interactions between variables is out of the scope of this work.

Temperature ranged from $155^{\circ} \mathrm{C}$ to $185^{\circ} \mathrm{C}$, pulping time ranged between $30 \mathrm{~min}$ and 90 min, alkali charge ranged between $10 \%$ and $20 \%$, anthraquinone charge ranged between $0 \%$ and $1 \%$, and the hydromodule ranged between 16 and 24 . The amount of $\mathrm{NaOH}$ or anthraquinone is expressed as grams of reagent per $100 \mathrm{~g}$ of dry raw material. In all assays, $25 \mathrm{~g}$ of $P$. oceanica (leaves or rhizome) were fractionated to a size lower than $20 \mathrm{~mm}$ and introduced into a 1-L glass reactor immersed in a thermostated oil bath. When the pulping time was up, cold deionized water was added to stop the reactions. The resultant fibers were filtered, washed with deionized water to remove caustic soda and anthraquinone, and dried at room temperature.

Table 1. Experimental Conditions for P. oceanica Pulping

\begin{tabular}{|c|c|c|c|c|c|}
\hline Assay & $\mathbf{T}(\mathbf{\circ} \mathbf{C})$ & $\mathbf{t}(\mathbf{m i n})$ & $\mathbf{S}(\%)$ & $\mathbf{A Q}(\%)$ & $\mathbf{L S}$ \\
\hline 1 & 185 & 60 & 15 & 0.5 & 20 \\
\hline 2 & 155 & 60 & 15 & 0.5 & 20 \\
\hline 3 & 170 & 90 & 15 & 0.5 & 20 \\
\hline 4 & 170 & 30 & 15 & 0.5 & 20 \\
\hline 5 & 170 & 60 & 20 & 0.5 & 20 \\
\hline 6 & 170 & 60 & 10 & 0.5 & 20 \\
\hline 7 & 170 & 60 & 15 & 1 & 20 \\
\hline 8 & 170 & 60 & 15 & 0 & 20 \\
\hline 9 & 170 & 60 & 15 & 0.5 & 24 \\
\hline 10 & 170 & 60 & 15 & 0.5 & 16 \\
\hline
\end{tabular}

$\mathrm{S}: \mathrm{g}$ of $\mathrm{NaOH}$ per $100 \mathrm{~g}$ of pulp, AQ: $\mathrm{g}$ of anthraquinone per $100 \mathrm{~g}$ of pulp, and LS: liquid-to-solid ratio

\section{Alkalization}

A pulp sample of $25 \mathrm{~g}$ (Table 1) was mixed with $500 \mathrm{~mL}$ of an aqueous $\mathrm{NaOH}$ solution into a 2-L stirred glass reactor (at $350 \mathrm{rpm}$ ). The concentration of caustic soda was $30 \%$ and the temperature was $23{ }^{\circ} \mathrm{C}$. After $60 \mathrm{~min}$, fibers were separated through a wire 
mesh filter with an aperture size of $400 \mu \mathrm{m}$ and washed with demineralized water. The pretreated samples were dried at room temperature.

Furthermore, to evaluate the influence of the amount of alkali, 6 other alkalization experiments were conducted during $60 \mathrm{~min}$ at three different $\mathrm{NaOH}$ dosages based on dry mass reagent per dry mass of the biomaterial $(10 \% \mathrm{w} / \mathrm{w}, 20 \% \mathrm{w} / \mathrm{w}$, and $30 \% \mathrm{w} / \mathrm{w})$ for leaves and rhizomes.

\section{Cationization}

Cationization took place in a 1-L three-mouthed spherical glass reactor with a refluxing condenser, a magnetic adjustable stirrer, heating controlled by an electronic PID device, and a Pt-100 probe to measure temperature, which was kept at $70{ }^{\circ} \mathrm{C}$. A material sample of $10 \mathrm{~g}$ (alkalized or pulped-alkalized material) was mixed with $500 \mathrm{~mL}$ of water and $2.465 \mathrm{~g}$ of $\mathrm{NaOH}$. Then, $33.5 \mathrm{~mL}$ of preheated cationizing agent CHPTAC was added to maintain a CHPTAC/AGU (anhydro glucose units) mole ratio of 4 . Collected samples were diluted in cold water to stop the reaction, and then samples were washed, filtered with wire mesh filters, and allowed to dry at room temperature.

\section{Characterization of alkalized samples}

The high elasticity of leaves and rhizomes from $P$. oceanica made them impossible to grind to a small particle size. Therefore, the authors submitted all samples to cryogenic milling with liquid nitrogen $\left(-196^{\circ} \mathrm{C}\right)$ and an agate mortar. X-ray diffraction patterns were produced using a powder X-ray diffractometer (X'Pert Powder, $\mathrm{Cu}-\mathrm{K} \alpha$ source, wavelength 0.154 nm, 40 mA; Malvern Panalytical, Madrid, Spain). Adopting the two-phase theory of structure and the amorphous halo correction, the crystallinity index (CI) was obtained from the diffractograms (Krässig 1996). A hyperbolic baseline correction and a Gaussian deconvolution of peaks were performed with Peakfit (Systat Software, v.4.12, San Jose, CA, USA).

\section{Analysis of cationized samples}

Carbon and nitrogen contents were determined by combustion on a LECO CNS2000I elemental macroanalyser (Leco Corporation, St. Joseph, MI, USA). Knowing the amounts of nitrogen incorporated as quaternary ammonium into cellulose by effect of the cationization treatment, the degree of substitution was determined. The carbon content was used to apply a correction to systematic errors.

The authors used a Charge Analysis System device from AFG Analytic GmbH (Leipzig, Germany) to measure the surface charge density. However, it was designed for liquids, so the authors opted for a back titration instead of a direct one. In each case, a small sample of cationized pulp was soaked in excess of an anionic polyelectrolyte, sodium polyvinylsulphate ( $3 \mathrm{~mL}$ of PVSNa, $1.8 \mathrm{mEq} / \mathrm{L}$ ). Demineralized water was added to make the solution up to $10 \mathrm{~mL}$. The liquid was titrated with a cationic polyelectrolyte, polydiallyldimethylammonium chloride (PDADMAC, $2.2 \mathrm{mEq} / \mathrm{L}$ ). The endpoint of the potentiometric titration was the isoelectric point $(0 \mathrm{mV})$.

Photographs were taken from a scanning electron microscope (SEM) (JEOL JSM6400; JEOL USA, Peabody, MA, USA). Each sample was placed on a cylindrical slide and, afterwards, in a vacuum oven at $45^{\circ} \mathrm{C}$ and $200 \mathrm{mbar}$ for $24 \mathrm{~h}$. Once dried, the sample was coated with gold (Q150T S Plus; Quorum Technologies, Lewes, UK). Then, it was visualized with magnifications of $500 \times$ and $1000 \times$. 


\section{RESULTS AND DISCUSSION}

\section{Effect of Alkalization on Crystallinity and Reactivity}

$\mathrm{X}$-ray diffraction measurements have been widely used to interpret changes in cellulose structure after physicochemical and biological treatments (Park et al. 2010). In this sense, XRD was applied to raw and alkalized $P$. oceanica fibers. The XRD patterns presented in Fig. 1 have undergone a normalization, so that the lowest intensity value from $10^{\circ}$ to $38^{\circ}$ was 0 and the highest value in that range was 1000 (arbitrary units). Except for the patterns corresponding to the highest alkali concentration (30\%), they were shifted to be shown in the same graph comprehensively. Miller indices were assigned to peaks and written according to the conventions used by French (2014). It can be safely assumed that the crystalline parts in fibers from $P$. oceanica leaf and $P$. oceanica rhizome, as lignocellulosic materials and unlike bacterial cellulose, consist mainly of cellulose I $\beta$. In the alkalized samples, a potential conversion into cellulose II should be considered.

The shape of the diffraction patterns observed for the untreated materials (Fig. 1) was typical of cellulose I, except for the prominent peaks located at $30^{\circ}$ for leaves and at $26.2^{\circ}$ for rhizomes. Because these peaks tend to disappear after the alkaline treatments, they were probably due to compounds that were extracted by pulping or alkalization. Bettaieb et al. (2015a) identified silica and weddellite $\left(\mathrm{CaC}_{2} \mathrm{O}_{4}-2 \mathrm{H}_{2} \mathrm{O}\right)$ in untreated $P$. oceanica. Peaks found at $15^{\circ}, 16.5^{\circ}, 22.2^{\circ}$, and $34.6^{\circ}$ corresponded to the crystallographic planes (1-10), (110), (200), and (004) of cellulose I $\beta$, respectively (Ferreira et al. 2018a).

With the alkaline treatments, the most prominent peak of cellulose I became slightly lopsided in the pattern of $P$. oceanica leaf (Fig. 1a). This likely indicated that a small amount of cellulose I $\beta$ was converted into cellulose II, as is well-known to happen in cotton mercerization (Yue et al. 2013). The normalized intensity was higher at $20.1^{\circ}$ and $21.5^{\circ}$, which corresponded to the planes (110) and (020), respectively, of cellulose II. However, the shape displayed by the treated samples in Fig. 1a still resembled a typical diffraction pattern of cellulose I. In contrast, for treated rhizomes (Fig. 1b), the height of the crystalline peak (020) of cellulose II was similar to that of the main peak of cellulose I.

Table 2 shows the $\mathrm{CI}$ of the starting and alkalized materials, calculated in two different ways. The area method, which is expected to give a more accurate estimation (Park et al. 2010), involved identifying, at least, the four most prevalent peaks of cellulose I and the peak (110) of cellulose II. The sum of their areas was then divided by the total area (Eq. 1). The height method, which relates the intensity for the plane (200) of cellulose I to the intensity of the amorphous scatter occurring around $18.5^{\circ}$ (Segal et al. 1959), is still more widely used in literature (Eq. 2). It should be noted that this estimation would produce lower values if the baseline subtraction were not performed. Equations 1 and 2 are as follows:

$$
\begin{aligned}
& C I(\text { area })=\frac{A_{1-10(I))}+A_{110(I \beta)}+A_{200(I \beta)}+A_{110(I I)}+A_{004}}{A_{\text {total }}} \\
& C I(\text { height })=1-\frac{I_{18.5, \min }}{I_{22.2, \text { max }}}
\end{aligned}
$$




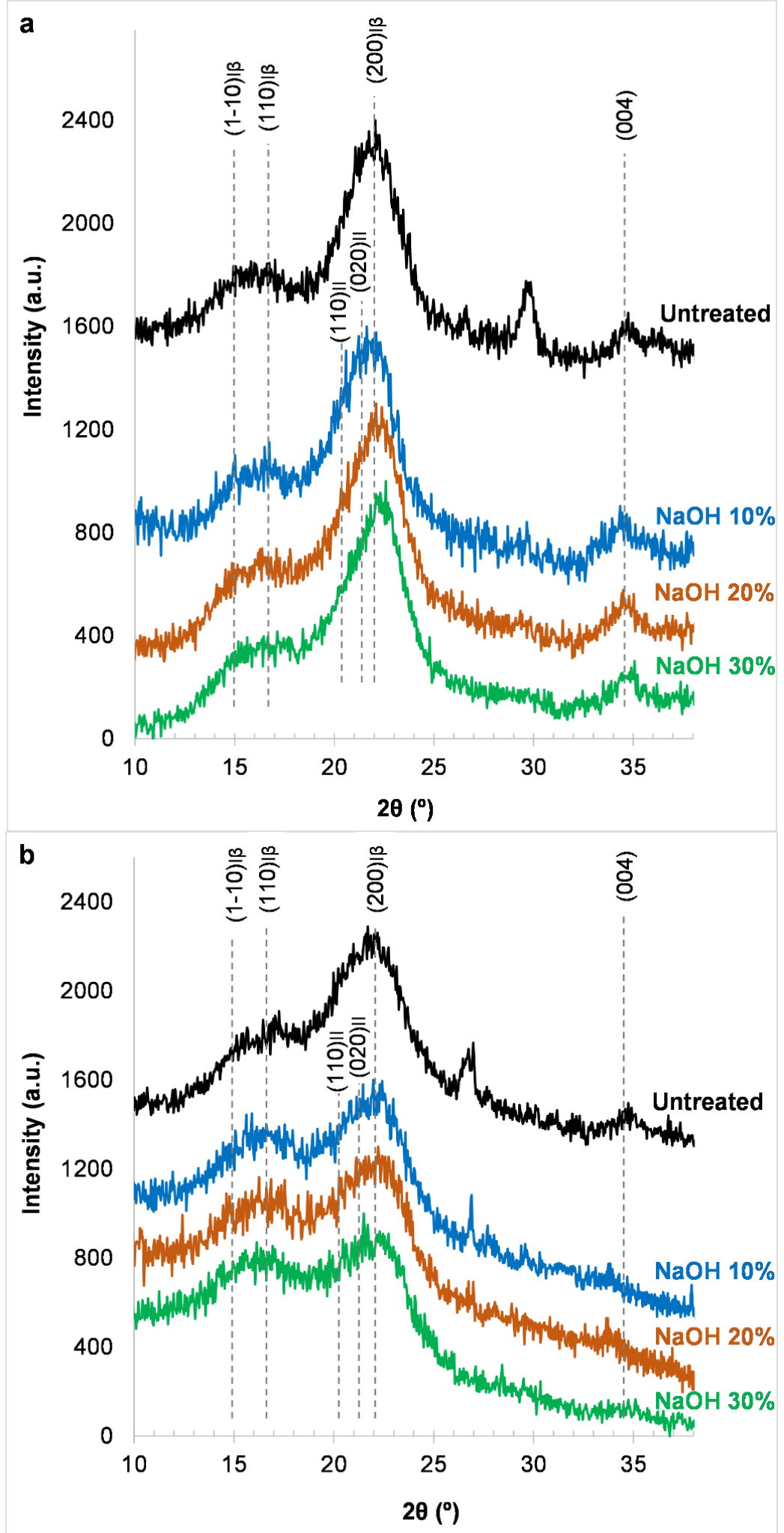

Fig. 1. XRD patterns of untreated and alkalized fibers $(10 \%, 20 \%$, and $30 \%$ dry mass $\mathrm{NaOH}$ per dry mass of biomaterial) of $P$. oceanica: (a) leaf and (b) rhizome 
For rhizomes (Fig. 1b), amorphization was more evident than for leaves (Fig. 1a), and thus the decrease in crystallinity calculated in Table 2 was more abrupt, from 0.67 to 0.42 (area) or from 0.81 to 0.37 (height). Unlike in the case of leaves, a $\mathrm{NaOH}$ dosage (dry $\mathrm{NaOH}$ per dry mass of biomass) of $10 \%$ was enough to achieve a great decrease in crystallinity. The peak for the plane (040) became nearly indiscernible. The intensity was much lower at the planes (110) and (200) of cellulose I, while the valley at $18^{\circ}$ to $18.5^{\circ}$, an indicator of the amorphous fraction, was higher. Additionally, decrystallization implied a notable peak broadening due to the appearance of interferences, particularly on the left and right side of the peak at $15^{\circ}$. It should be noted that this broadening contributed to the amorphous area and was not included in the area of crystalline peaks, as a deconvolution approach had been followed (Foster et al. 2018). Both conversions, the one from cellulose I $\beta$ to cellulose II and the one from any of those crystalline polymorphs to amorphous cellulose, occurred to a higher extent in rhizomes.

Amorphization was observed to have a positive influence on cationization (Table 2). Breaking down intermolecular and intramolecular hydrogen bonds makes cellulose more prone to chemical modifications. Moreover, the previous delignification step exposes cellulose surface more favorably to a cationization process. A high concentration of caustic soda allowed the authors to produce cationic $P$. oceanica leaves with a nitrogen percentage of $1.5 \%$ after $120 \mathrm{~min}$, which is in the high range for cationic fibers (Moral et al. 2016). This was translated in a charge density of $0.61 \mathrm{mEq} / \mathrm{g}$. Considering that the negative surface charge of a bleached hardwood kraft pulp is approximately $0.025 \mathrm{mEq} / \mathrm{g}$ (Sood et al. 2010), a small addition of cationic leaves (4\%) would be enough to switch the global charge from negative to positive. Despite the more evident amorphization of rhizomes, it was impossible to achieve high cationicity with this material. Its structure and its remaining lignin hindered the mass transfer.

Table 2. Effect of Alkalization on the Crystallinity Index, and on the Substitution and the Charge Density after Cationization

\begin{tabular}{|c|c|c|c|c|c|c|c|c|}
\hline Material & \multicolumn{4}{|c|}{$\boldsymbol{P}$. oceanica Leaf } & \multicolumn{4}{c|}{ P. oceanica Rhizome } \\
\hline $\mathrm{NaOH}$ Dosage (dry wt\%) & 0 & 10 & 20 & 30 & 0 & 10 & 20 & 30 \\
\hline $\mathrm{Cl}$, Area Method & 0.65 & 0.61 & 0.58 & 0.56 & 0.67 & 0.48 & 0.42 & 0.44 \\
\hline $\mathrm{Cl}$ Height Method & 0.79 & 0.62 & 0.58 & 0.57 & 0.81 & 0.49 & 0.45 & 0.37 \\
\hline $\mathrm{N}(\%)$ & - & 1.3 & 1.4 & 1.5 & - & 0.99 & 1.1 & 1.3 \\
\hline $\mathrm{CD}(\mathrm{mEq} / \mathrm{g})$ & - & 0.44 & 0.54 & 0.61 & - & 0.15 & 0.23 & 0.29 \\
\hline
\end{tabular}

$\mathrm{Cl}$ : Crystallinity index, CD: Charge density

\section{Impact of the Treatments on Morphology}

Cellulose accessibility is determined by crystallinity, but is also likely to be affected by the content and distribution of hemicellulose and remaining lignin on the fiber surface, porosity, particle size, and specific surface area. During pulping, alkalization, and cationization, $P$. oceanica fibers were exposed to physical and chemical modifications that resulted in changes of their original morphology. Figure 2 shows the original surface of leaves and rhizomes before the treatments, compared to the surfaces of alkalized samples. The original surface was smooth and uniform, fibrillation was negligible, and thus the specific surface area was low. Leaves from $P$. oceanica are a highly structured material with a fibrous aspect, as observed by Allouche et al. (2011). These authors also found lamellar structures in the outer layers, while the central part of the material in tape form presented a less structured appearance. Additionally, Ncibi et al. (2009) concluded by 
electron microscope observation that raw biomass from $P$. oceanica is a nonporous and fibrous compact.
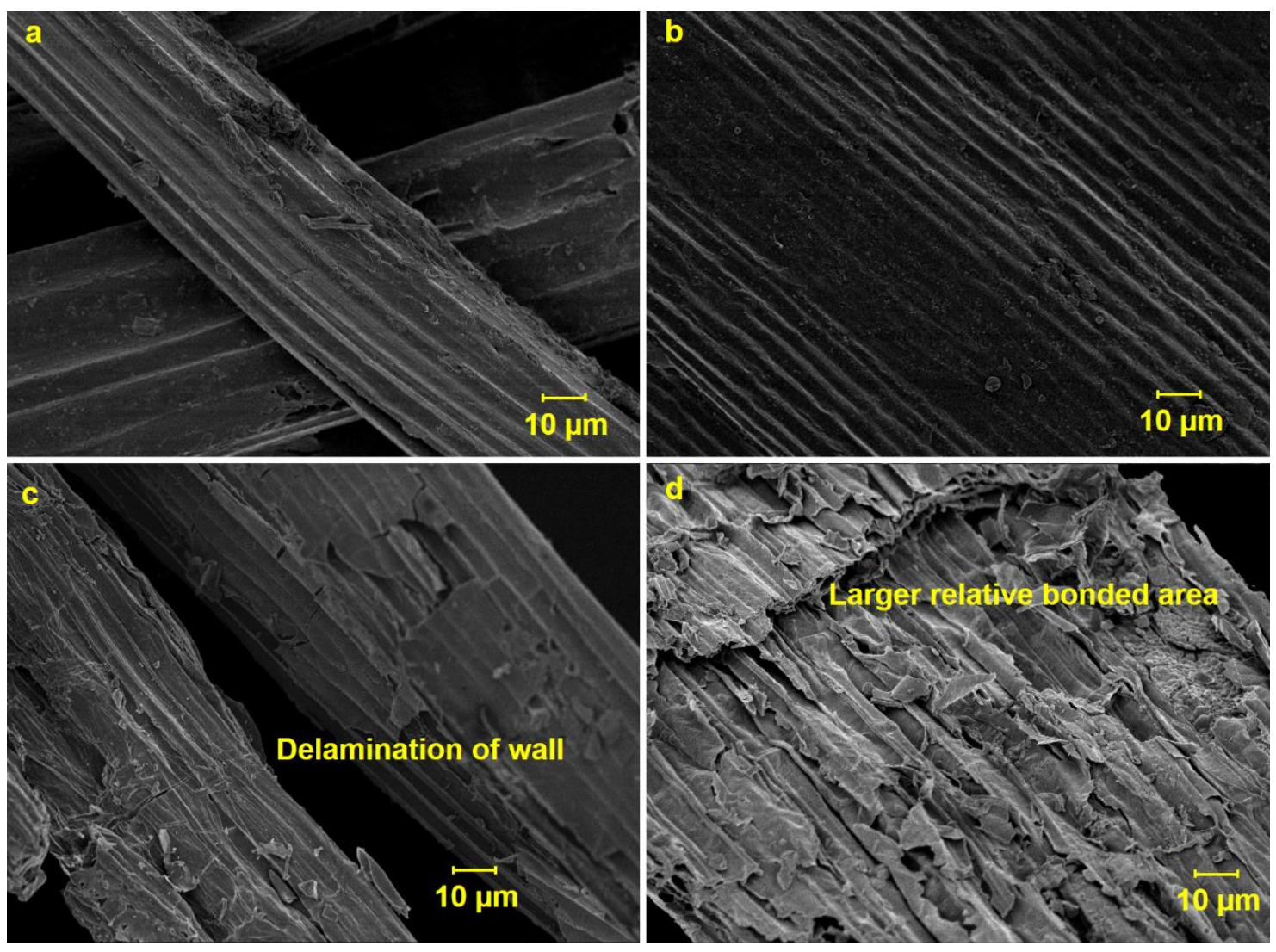

Fig. 2. SEM images at $500 \times$ : (a) untreated rhizome; (b) untreated leaf; (c) alkalized rhizome $(\mathrm{NaOH} 30 \%, 60 \mathrm{~min})$; and (d) alkalized leaf $(\mathrm{NaOH} 30 \%, 60 \mathrm{~min})$

The fibers of the rhizomes (Fig. 2a) had smaller diameters than the fibers of the leaves (Fig. 2b). These results were consistent with previous research that concluded that depending on its origin, the cellulose microfibrils may have transverse dimensions ranging from $20 \mathrm{~nm}$ to $200 \mathrm{~nm}$, but these particles are often aggregates, and individual microfibrils are usually in the range of $3 \mathrm{~nm}$ to $20 \mathrm{~nm}$ (Sassi and Chanzy 1995). Thus, the fibers of the rhizomes would consist of cellulosic microfibrils agglomerated by hemicellulose and lignin, while in leaves lignin is present in smaller proportions (Kuo and Cambridge 1978; Ncibi et al. 2009; Bettaieb et al. 2015a). Figure 3 also shows that $P$. oceanica rhizomes had a structure with a higher number of fibers than leaves. In the images taken for leaves, other cellular elements, such as parenchyma, vascular tissues, and cellular epidermis, were observed. These fibers exhibited large lumen width, with the outer cells thicker than the inner cells. Bettaieb et al. (2015a) studied morphological differences between leaves and balls from $P$. oceanica using SEM. They found a porous structure in leaves compared to the balls, which show a similar structure to the rhizomes analyzed in this paper.

Figure $2 \mathrm{c}$ and $2 \mathrm{~d}$ show the fibers of rhizomes and leaves of $P$. oceanica after alkalization of raw material under the harshest conditions. The fibers appeared separated in micrometric filaments, and showed a reduction in the diameter when compared to the raw materials. Fibrillation was apparent, as the fiber wall was heavily damaged. The transition from smooth surfaces to rough surfaces after treatments with $\mathrm{NaOH}$ was mainly 
attributable to the removal of the hemicellulose layer, which surround cellulose fibrils, and to a partial removal of lignin (Ferreira et al. 2018b).

A higher degree of substitution (DS) during cationization seemed to promote a more intense attack on fibers and a less ordered structure in the fibrils (Fig. 3). After pulping, alkalization, and the insertion of many quaternary ammonium groups in the cellulose chains, the wall was nearly destroyed (Fig. 3a and 3c). Even when the degree of nitrogen substitution was low, many microfibrils were protruding from the fiber surface (Fig. 3b and 3d).
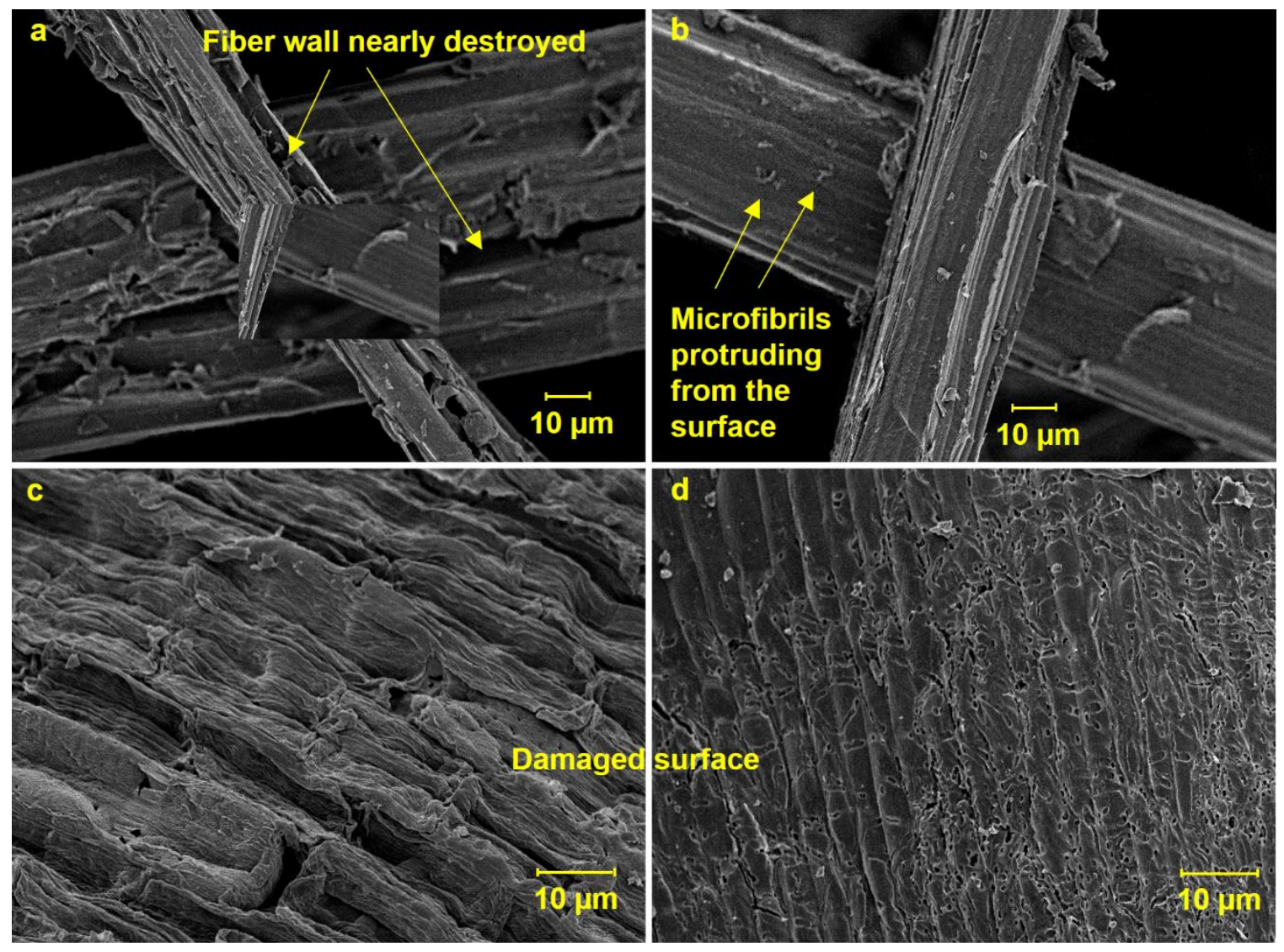

Fig. 3. SEM images of alkalized and cationized pulps: (a) from rhizomes, high DS (500x); (b) from rhizomes, low DS (500x); (c) from leaves, high DS (1000x); and (d) from leaves, low DS $(1000 x)$

\section{Cationization Kinetics}

After pulping-alkalization-cationization of rhizomes and leaves of $P$. oceanica, the percentage of nitrogen incorporated into cellulose was measured by elemental analysis, and the results are shown in Fig. 4. As the figure reveals, the increase in the percentage of nitrogen incorporated in cellulose from $P$. oceanica was more pronounced in the first minutes of cationization. It leveled off before $70 \mathrm{~min}$ of reaction. Additionally, it was deduced that cationization was more effective in leaves than in rhizomes. This was explained, as previously observed in the SEM analyses, based on the fact that the fibers of the rhizomes were formed by agglomerated microfibrils with a greater amount of lignin. In other words, the low degrees of substitution found for cationized rhizomes were due to mass transfer limitations. In addition, alkalization greatly increased the specific surface area of leaves. 


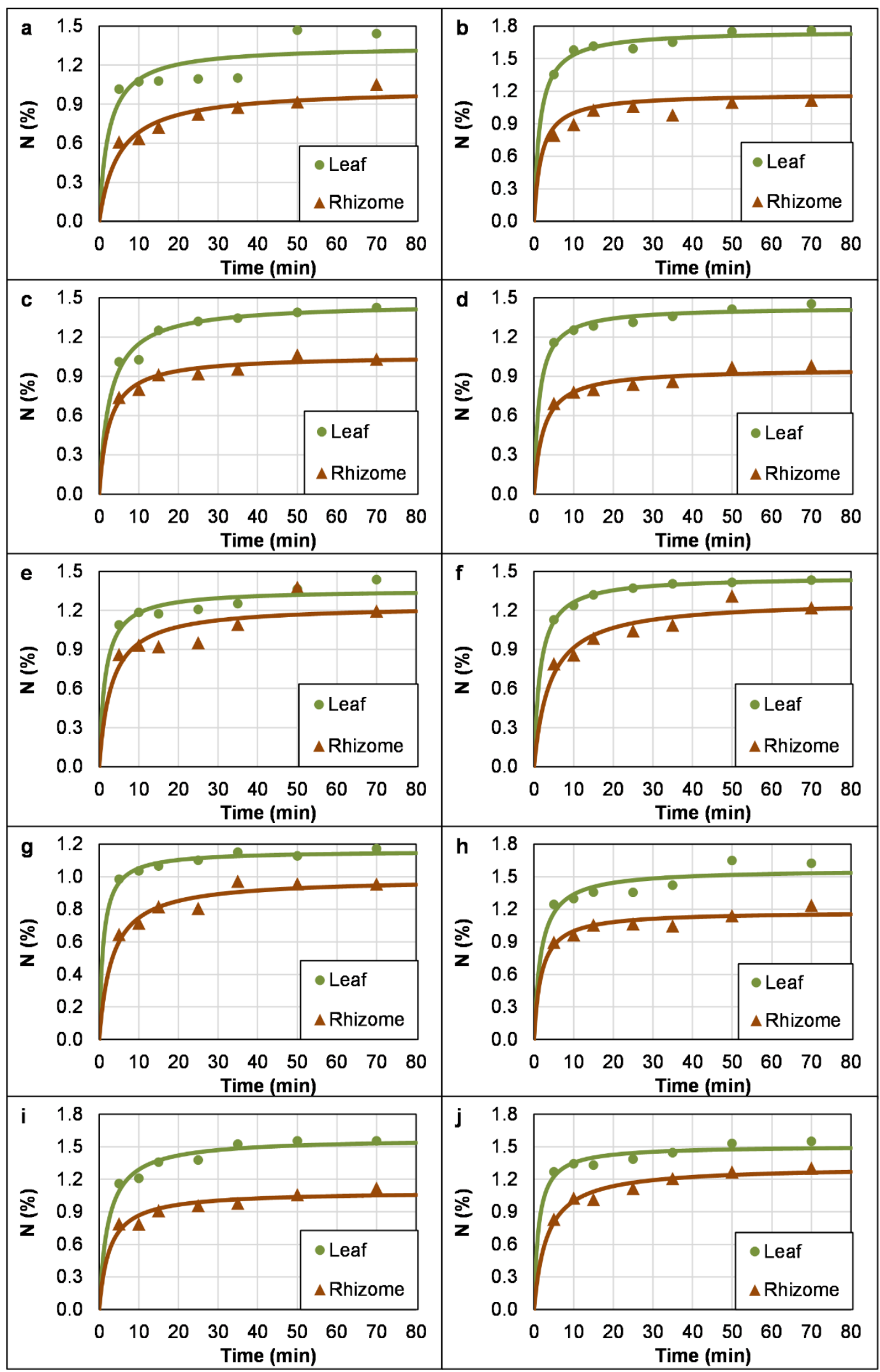

Fig. 4. Percentage of nitrogen incorporated as quaternary ammonium ions into cellulose from leaves (O) and rhizomes $(\boldsymbol{\Delta})$ : (A) high $T,(B)$ low $T,(C)$ high $t,(D)$ low $t,(E)$ high $S,(F)$ low $S,(G)$ high $A Q,(H)$ low $A Q$, (I) high LS, and $(J)$ low LS 
In previous kinetic studies with microcrystalline cellulose and cotton linters (Moral et al. 2016), the authors found that the percentage of nitrogen incorporated as quaternary ammonium ions into cellulose could be fitted to a pseudo-second-order (PSO) rate equation. This approach was based on a theoretical background examined by Azizian (2004). Kinetic constants of pseudo-second-order models are combinations of the initial solute concentration and the adsorption and desorption parameters, as the adsorption behavior which is characteristic of the PSO model can be explained by diffusion-based mechanisms (Hubbe et al. 2019). Once integrated with the proper boundary condition $(N$ $(\%)$ is zero at time zero), this model is:

$$
N(\%)=\frac{k \cdot N_{e q}{ }^{2} \cdot t}{1+k \cdot N_{e q} \cdot t}
$$

Parameters $k$ and $N_{\mathrm{eq}}$ are shown in Table 3. Fitting always achieved a high coefficient of determination.

Table 3. Parameters of a Pseudo-second-order Rate Equation for All Cationizations

\begin{tabular}{|c|c|c|c|c|c|c|}
\hline \multirow{2}{*}{ Assay } & \multicolumn{3}{|c|}{ Leaf } & \multicolumn{3}{c|}{ Rhizome } \\
\cline { 2 - 6 } & $k\left(\mathrm{~min}^{-1}\right)$ & $N_{\text {eq }}(\%)$ & $\mathrm{R}^{2}$ & $k\left(\mathrm{~min}^{-1}\right)$ & $N_{\text {eq }}(\%)$ & $\mathrm{R}^{2}$ \\
\hline 1 & 0.312 & 1.35 & 0.907 & 0.200 & 1.02 & 0.961 \\
\hline 2 & 0.389 & 1.76 & 0.994 & 0.468 & 1.18 & 0.982 \\
\hline 3 & 0.252 & 1.46 & 0.985 & 0.376 & 1.06 & 0.987 \\
\hline 4 & 0.537 & 1.43 & 0.995 & 0.449 & 0.96 & 0.982 \\
\hline 5 & 0.485 & 1.36 & 0.978 & 0.262 & 1.24 & 0.910 \\
\hline 6 & 0.441 & 1.46 & 0.999 & 0.195 & 1.28 & 0.966 \\
\hline 7 & 0.842 & 1.16 & 0.997 & 0.311 & 0.99 & 0.979 \\
\hline 8 & 0.367 & 1.57 & 0.967 & 0.468 & 1.18 & 0.982 \\
\hline 9 & 0.281 & 1.58 & 0.987 & 0.356 & 1.09 & 0.975 \\
\hline 10 & 0.566 & 1.51 & 0.989 & 0.235 & 1.32 & 0.988 \\
\hline
\end{tabular}

In Fig. 5, the results were expressed as the DS, i.e., the average number of positively-charged groups per cellulose monomer, according to Eq. 4,

$$
D S=\frac{162.15(\% N)}{1401-151.64(\% N)}
$$

where 162.15 is the molecular weight of the anhydroglucose unit (AGU), \%N denotes the percentage (\%) of dry elemental nitrogen, 1401 is 100 times the atomic weight of nitrogen, and 151.64 is the molecular weight of the 2,3-epoxypropyltrimethylammonium chloride (EPTMAC) group added.

Temperature during pulping unfavorably affected the subsequent cationization of the fibers (Fig. 5a and 5b). This was more notable in the assays with leaves, where DS was reduced from 0.252 to 0.203 (Fig. 5a). The rate of the hydrolysis of amorphized cellulose, less stable and more prone to cationization, increased with increasing temperature, thus leaving a less reactive material before cationization. Time and the concentration of soda had little effect on cationization. Unexpectedly, the amount of anthraquinone showed a strong negative impact, with a DS reduction of $33 \%$ in the leaves and $24 \%$ in rhizomes. Anthraquinone might have protected the cellulose chains on the fiber surface, which made them more stable before alkalization. 
With little influence from the pulping conditions, except for temperature and anthraquinone, the authors recommend cooking the dead biomass from $P$. oceanica under mild conditions, with caustic soda but without anthraquinone, for a short time. This would help make the global process more economically and environmentally feasible. The process could even finish in less than $3 \mathrm{~h}$, and the highest temperature reached was $155^{\circ} \mathrm{C}$.

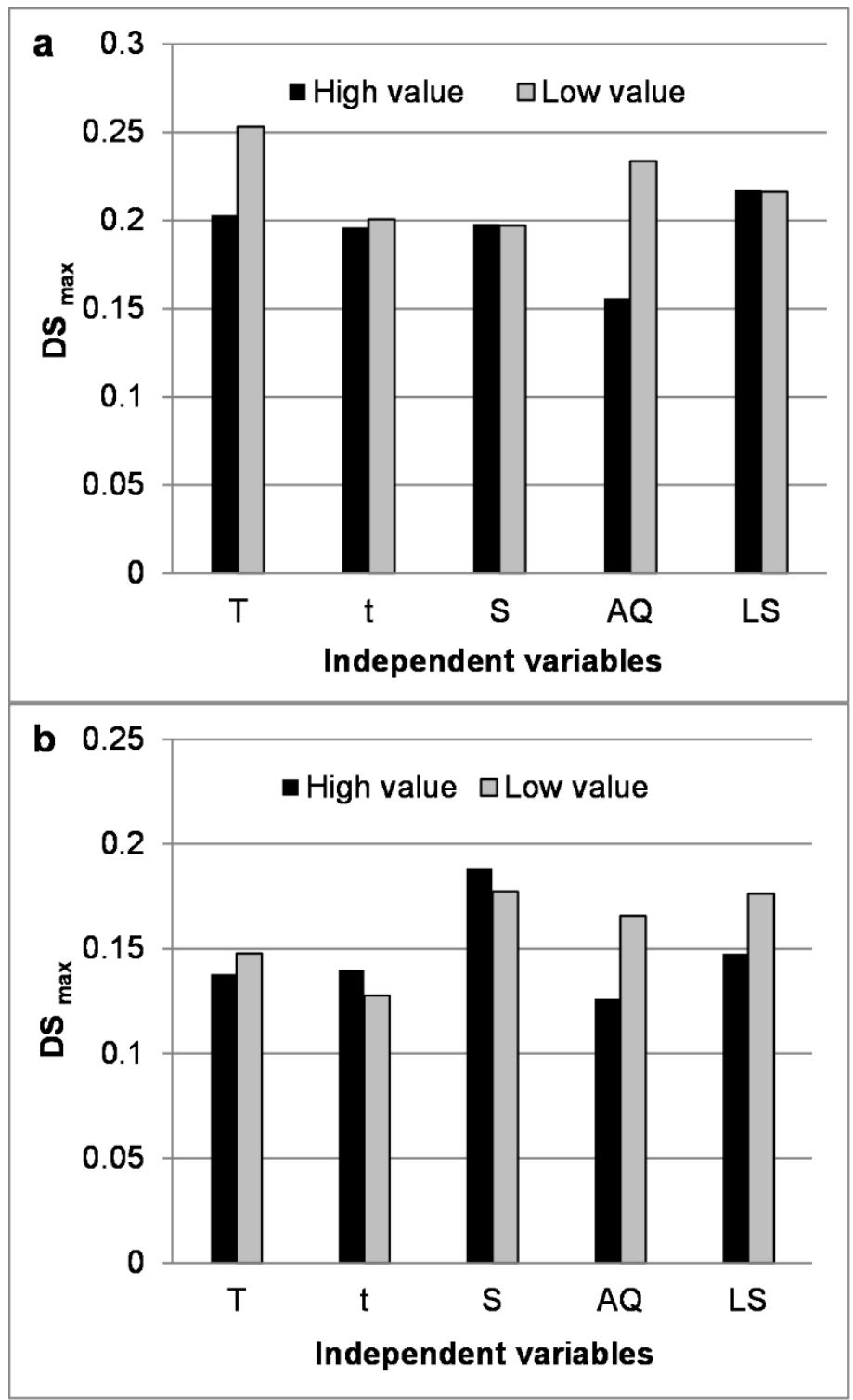

Fig. 5. Maximum DS obtained after pulping-alkalization-cationization of cellulose fibers of (a) leaves, and (b) rhizome of $P$. oceanica. Black and grey bars represent the assays with the most and least severe conditions during pulping, respectively.

\section{CONCLUSIONS}

1. Short times and mild conditions were enough to produce cationic cellulosic fibers from $P$. oceanica. After only $1 \mathrm{~h}$ of pulping, $1 \mathrm{~h}$ of alkaline treatment (to decrease the crystallinity of pulps), and 70 min of cationization, the material had between 10 
quaternary ammonium groups per 100 anhydroglucose units to 25 quaternary ammonium groups per 100 anhydroglucose units. The degrees of substitution reached by leaves were higher than those achieved by rhizomes, even though the latter were found to have less amorphous cellulose before functionalization. Kinetics of cationization were successfully fitted to a pseudo-second-order rate equation, which evidenced the importance of mass transfer limitations. The rhizome tissue was significantly harder to penetrate.

2. Seagrasses, particularly P. oceanica in the case of the Mediterranean Sea, have good potential as sources of cellulosic fibers, and chemical modifications to them do not require severe conditions. In fact, increasing the reaction time and the concentration of $\mathrm{NaOH}$ had no appreciable effect on the degree of substitution. Dead biomass along coastlines could be valorized towards cationic cellulosic fibers whose usage could aid the dyeing process in the textile industry or sheet formation in papermaking.

\section{ACKNOWLEDGMENTS}

The authors acknowledge Pablo de Olavide University (Seville, Spain) for financial support. The authors are also thankful to the Auxiliary Research Centers of Complutense University of Madrid (Madrid, Spain).

\section{REFERENCES CITED}

Aguir, C., and M'Henni, M. F. (2006). "Experimental study on carboxymethylation of cellulose extracted from Posidonia oceanica," J. Appl. Polym. Sci. 99(4), 1808-1816. DOI: 10.1002/app.22713

Alcoverro, T., Duarte, C. M., and Romero, J. (1995). "Annual growth dynamics of Posidonia oceanica: Contribution of large-scale versus local factors to seasonality," Mar. Ecol. Prog. Ser. 120(1-3), 203-210. DOI: 10.3354/meps120203

Allouche, F.-N., Mameri, N., and Guibal, E. (2011). "Pb(II) biosorption on Posidonia oceanica biomass," Chem. Eng. J. 168(3), 1174-1184. DOI: 10.1016/j.cej.2011.02.005

Azizian, S. (2004). "Kinetic models of sorption: A theoretical analysis," Journal of Colloid and Interface Science 276, (1) 47-52. DOI: 10.1016/j.jcis.2004.03.048 •

Benito-González, I., López-Rubio, A., and Martínez-Sanz, M. (2018). "Potential of lignocellulosic fractions from Posidonia oceanica to improve barrier and mechanical properties of bio-based packaging materials," Int. J. Biol. Macromol. 118, 542-551. DOI: 10.1016/j.ijbiomac.2018.06.052

Benito-González, I., López-Rubio, A., Gavara, R., and Martínez-Sanz, M. (2019). "Cellulose nanocrystal-based films produced by more sustainable extraction protocols from Posidonia oceanica waste biomass," Cellulose 26(13-14), 8007-8024. DOI: 10.1007/s10570-019-02641-4

Bettaieb, F., Khiari, R., Dufresne, A., Mhenni, M. F., Putaux, J. L., and Boufi, S. (2015a). "Nanofibrillar cellulose from Posidonia oceanica: Properties and morphological features," Ind. Crop. Prod. 72, 97-106. DOI: 10.1016/j.indcrop.2014.12.060

Bettaieb, F., Khiari, R., Hassan, M. L., Belgacem, M. N., Bras, J., Dufresne, A., and 
Mhenni, M. F. (2015b). "Preparation and characterization of new cellulose nanocrystals from marine biomass Posidonia oceanica," Ind. Crop. Prod. 72, 175182. DOI: $10.1016 / j$.indcrop.2014.12.038

Cansee, S., Uriyapongson, J., Watyotha, C., Thivavarnvongs, T., and Varith, J. (2008). "Amphoteric starch in simultaneous process preparation with Box-Behnken design for optimal conditions," Am. J. Appl. Sci. 5(11), 1535-1542. DOI: 10.3844/ajassp.2008.1535.1542

Chopin, N., Guillory, X., Weiss, P., Le Bideau, J., and Colliec-Jouault, S. (2014).

"Design polysaccharides of marine origin: Chemical modifications to reach advanced versatile compounds," Curr. Org. Chem. 18(7), 867-895. DOI: $10.2174 / 138527281807140515152334$

Coletti, A., Valerio, A., and Vismara, E. (2013). "Posidonia oceanica as a renewable lignocellulosic biomass for the synthesis of cellulose acetate and glycidyl methacrylate grafted cellulose," Materials 6(5), 2043-2058. DOI: 10.3390/ma6052043

Ferreira, F. V., Mariano, M., Rabelo, S. C., Gouveia, R. F., and Lona, L. M. F. (2018b). "Isolation and surface modification of cellulose nanocrystals from sugarcane bagasse waste: From a micro- to a nano-scale view, "Appl. Surf. Sci 436, 1113-1122. DOI: 10.1016/j.apsusc.2017.12.137

Ferreira, F. V., Pinheiro, I. F., Gouveia, R. F., Thim, G. P., and Lona, L. M. F. (2018a). "Functionalized cellulose nanocrystals as reinforcement in biodegradable polymer nanocomposites," Polym. Compos. 39(S1), E9-E29. DOI: 10.1002/pc.24583

Fortunati, E., Luzi, F., and Torre, L. (2017). "Chapter 16: PLA nanocomposites from Posidonia oceanica waste," in: Jawaid, M., Tahir, P. M., and Saba, N. (eds.), Lignocellulosic Fibre and Biomass-Based Composite Materials: Processing, Properties and Applications, Woodhead Publishing, pp. 347-363. DOI: 10.1016/B978-0-08-100959-8.00016-0

Foster, E. J., Moon, R. J., Agarwal, U. P., Bortner, M. J., Bras, J., Camarero-Espinosa, S. , Chan, K. J. , Clift, M. J. D. , Cranston, E. D. , Eichhorn, S.J. et al. (2018). "Current characterization methods for cellulose nanomaterials," Chem. Soc. Rev. 47(8), 2609-2679. DOI: 10.1039/C6CS00895J

French, A. D. (2014). "Idealized powder diffraction patterns for cellulose polymorphs," Cellulose 21(2), 885-896. DOI: 10.1007/s10570-013-0030-4

Hubbe, M. A., Azizian, S., and Douven, S. (2019). "Implications of apparent pseudosecond-order adsorption kinetics onto cellulosic materials. A review," BioResources 14(3), 7582-7626. DOI: 10.15376/biores.14.3.7582-7626

Kavaliauskaite, R., Klimaviciute, R., and Zemaitaitis, A. (2008). "Factors influencing production of cationic starches," Carbohyd. Polym. 73(4), 665-675. DOI: 10.1016/j.carbpol.2008.01.019

Khiari, R., Mhenni, M. F., Belgacem, M. N., and Mauret, E. (2011). "Valorisation of vegetal wastes as a source of cellulose and cellulose derivatives," J. Polym. Environ. 19(1), 80-89. DOI: 10.1007/s10924-010-0207-y

Klap, V. A., Hemminga, M. A., and Boon, J. J. (2000). "Retention of lignin in seagrasses: Angiosperms that returned to the sea," Mar. Ecol. Prog. Ser. 194, 1-11. DOI: 10.3354/meps 194001

Knoshaug, E. P., Shi, B., Shannon, T. G., Mleziva, M. M., and Pienkos, P. T. (2013). "The potential of photosynthetic aquatic species as sources of useful cellulose fibers A review," J. Appl. Phycol. 25(4), 1123-1134. DOI: 10.1007/s10811-012-9958-2 
Krässig, H. A. (1996). Cellulose: Structure, Accessibility and Reactivity, 2nd edition, Gordon and Breach Science Publishers, Singapore, pp. 167-169.

Kuo, J., and Cambridge, M. L. (1978). "Morphology, anatomy and histochemistry of the Australian seagrasses of the genus Posidonia könig (Posidoniaceae). II. Rhizome and root of Posidonia australis Hook. f," Aquat. Bot. 5, 191-206. DOI: 10.1016/03043770(78)90061-X

Lepoint, G., Defawe, O., Gobert, S., Dauby, P., and Bouquegneau, J.-M. (2002). "Experimental evidence for $\mathrm{N}$ recycling in the leaves of the seagrass Posidonia oceanica," J. Sea Res. 48(3), 173-179. DOI: 10.1016/S1385-1101(02)00164-8

Liitiä, T., Rovio, S., Talja, R., Tamminem, T., Rencoret, J., Gutiérrez Suárez, A., Del Río, J. C., Saake, B., Schwartz, K., Babarro, V., et al. (2014). "Structural characteristics of industrial lignins in respect to their valorization," in: Proceedings of the $13^{\text {th }}$ European Workshop on Lignocellulosics and Pulp, Seville, Spain, pp. 79-82.

Moral, A., Aguado, R., and Tijero, A. (2016). "Alkalization and cationization of cellulose: Effects on intrinsic viscosity," Fiber. Polym. 17(6), 857-861. DOI: 10.1007/s12221-016-5819-y

Ncibi, M. C., Jeanne-Rose, V., Mahjoub, B., Jean-Marius, C., Lambert, J., Ehrhardt, J. J., Bercion, Y., Seffen, M., and Gaspard, S. (2009). "Preparation and characterisation of raw chars and physically activated carbons derived from marine Posidonia oceanica (L.) fibres," J. Hazard. Mater. 165(1-3), 240-249. DOI:

10.1016/j.jhazmat.2008.09.126

Park, S., Baker, J. O., Himmel, M. E., Parilla, P. A., and Johnson, D. K. (2010). "Cellulose crystallinity index: Measurement techniques and their impact on interpreting cellulase performance," Biotechnol. Biofuel. 3(1), Article Number 10. DOI: $10.1186 / 1754-6834-3-10$

Percival, E. G. V., and Ross, A. G. (1949). "Marine algal cellulose," J. Chem. Soc. 1949, 3041-3043.

Peter, G., and Neale, D. (2004). "Molecular basis for the evolution of xylem lignification," Curr. Opin. Plant Biol. 7(6), 737-742. DOI: 10.1016/j.pbi.2004.09.002

Prado, H. J., and Matulewicz, M. C. (2014). "Cationization of polysaccharides: A path to greener derivatives with many industrial applications," Eur. Polym. J. 52, 53-75. DOI: 10.1016/j.eurpolymj.2013.12.011

Ruíz, J. M., Boudouresque, C. F., and Enríquez, S. (2009). "Mediterranean seagrasses," Bot. Mar. 52(5), 369-381. DOI: 10.1515/BOT.2009.058

Saini, S., Falco, C. Y., Belgacem, M. N., and Bras, J. (2016). "Surface cationized cellulose nanofibrils for the production of contact active antimicrobial surfaces," Carbohydr. Polym. 135, 239-247. DOI: 10.1016/j.carbpol.2015.09.002

Sassi, J.-F., and Chanzy, H. (1995). "Ultrastructural aspects of the acetylation of cellulose," Cellulose 2(2), 111-127. DOI: 10.1007/BF00816384

Segal, L., Creely, J. J., Martin, A. E., and Conrad, C. M. (1959). "An empirical method for estimating the degree of crystallinity of native cellulose using the X-ray diffractometer," Text. Res. J. 29(10), 786-794. DOI: 10.1177/004051755902901003

Short, F., Carruthers, T., Dennison, W., and Waycott, M. (2007). "Global seagrass distribution and diversity: A bioregional model," J. Exp. Mar. Biol. Ecol. 350(1-2), 320. DOI: 10.1016/j.jembe.2007.06.012

Song, Y., Sun, Y., Zhang, X., Zhou, J., and Zhang, L. (2008). "Homogeneous quaternization of cellulose in $\mathrm{NaOH} /$ urea aqueous solutions as gene carriers," Biomacromolecules 9(8), 2259-2264. DOI: 10.1021/bm800429a 
Sood, Y. V., Tyagi, R., Tyagi, S., Pande, P. C., and Tondon, R. (2010). "Surface charge of different paper making raw materials and its influence on paper properties," J. Sci. Ind. Res. 69(4), 300-304.

Syed, N. N. F., Zakaria, M. H., and Bujang, J. S. (2016). "Fiber characteristics and papermaking of seagrass using hand-beaten and blended pulp," BioResources 11(2), 5358-5380. DOI: 10.15376/biores.11.2.5358-5380

Tang, Y., Rosenberg, J. N., Bohutskyi, P., Yu, G., Betenbaugh, M. J., and Wang, F. (2016). "Microalgae as a feedstock for biofuel precursors and value-added products: Green fuels and golden opportunities," BioResources 11(1), 2850-2885. DOI: 10.15376/biores.11.1.Tang

Yan, L., Tao, H., and Bangal, P. R. (2009). "Synthesis and flocculation behavior of cationic cellulose prepared in a NaOH/ urea aqueous solution," CLEAN - Soil, Air, Water 37(1), 39-44. DOI: 10.1002/clen.200800127

Yue, Y., Han, G., and Wu, Q. (2013). "Transitional properties of cotton fibers from cellulose I to cellulose II structure," BioResources 8(4), 6460-6471. DOI: 10.15376/biores.8.4.6460-6471

Article submitted: June 26, 2019; Peer review completed: September 2, 2019; Revised version received and accepted: September 16, 2019; Published: October 4, 2019.

DOI: 10.15376/biores.14.4.9228-9243 